\title{
Evidence-based recommendations for the use of WBC-reduced cellular blood components
}

\author{
Thomas A. Ratko, Joseph P. Cummings, Harold A. Oberman, Kendall P. Crookston, \\ Phillip J. DeChristopher, D. Ted Eastlund, John E. Godwin, Ronald A. Sacher, \\ David H. Yawn, and Karl A. Matuszewski
}

I $\mathrm{n}$ the United States, approximately 12 million to 14 million units of blood are donated annually. ${ }^{1}$ These units typically are fractionated into some 20 million blood components, mainly RBCs, platelets, and FFP. ${ }^{2}$ Alternatively, plasma, RBCs, and platelets may be obtained by apheresis. On average, 3 million to 4 million patients receive

ABBREVIATIONS: DHHS = Department of Health and Human Services; FNHTR(s) = febrile nonhemolytic transfusion reaction(s); HHV-8 = human herpesvirus 8; LOS = length of stay; $\mathrm{PC}(\mathrm{s})=$ platelet concentrate(s); TRALI = transfusion-related acute lung injury; UHC = University HealthSystem Consortium; ULR = universal leukoreduction; VATS = Viral Activation Transfusion Study; vCJD = variant CJD.

From the Technology Assessment Group, Clinical Practice Advancement Center, University HealthSystem Consortium, Oak Brook, Illinois; the Department of Pathology, University of Michigan, Ann Arbor, Michigan; the Department of Transfusion Medicine and Coagulation, University of New Mexico Health Science Center, Albuquerque, New Mexico; the Blood Bank and Transfusion Medicine, University of Illinois at Chicago Medical Center; and the Hematology Clinical Laboratories, Loyola University Medical Center, Chicago, Illinois; the Division of Transfusion Medicine, Fairview-University Medical Center, Minneapolis, MN; Hoxworth Blood Center, University of Cincinnati Medical Center, Cincinnati, Ohio; and the Department of Pathology, Baylor College of Medicine, Dallas, Texas.

Address reprint requests to: Thomas A. Ratko, $\mathrm{PhD}$, Clinical Practice Advancement Center, University HealthSystem Consortium, 2001 Spring Road, Suite 700, Oak Brook, IL 60523-1890; e-mail: ratko@uhc.edu.

The recommendations reported herein are not those of the American Red Cross, the FDA, or the US Department of Health and Human Services.

Received for publication March 6, 2001; revision received May 8, 2001, and accepted May 25, 2001.

TRANSFUSION 2001;41:1310-1319. blood transfusions annually, with overall costs of blood services estimated to be 1 percent of health care expenditures. ${ }^{3,4}$

Although current fractionation procedures are highly effective, significant numbers ofWBCs remain in RBCs and platelets that are prepared from whole blood. ${ }^{5,6}$ Evidence from published clinical studies implicates residual allogeneicWBCs in transfused components as a cause of HLA alloimmunization, platelet refractoriness, CMV transmission, and febrile nonhemolytic transfusion reactions (FNHTRs). ${ }^{5,7,8}$ Passenger WBCs have been associated with a number of other adverse transfusion-related effects, such as immunomodulation, ${ }^{9-12}$ and the transmission of prion diseases, such as variant CJD (vCJD). ${ }^{13}$ However, clinical data to date are either inconsistent or insufficient to prove any of the latter associations.

In September 1998, the FDA Blood Products Advisory Committee unanimously affirmed the following question: "Is the benefit-to-risk ratio associated with leukoreduction [WBC reduction] sufficiently great to justify requiring the ULR [universal leukoreduction] of all non-leukocyte cellular transfusion components, irrespective of the theoretical considerations for transfusion-transmitted CJD?" In January 2001, the Advisory Committee on Blood Safety and Availability of the Department of Health and Human Services (DHHS) voted to recommend that the FDA implement ULR in the United States as soon as feasible. Thus, the FDA likely will begin the process that would ultimately make WBC reduction a manufacturing requirement for blood providers, thereby converting the US blood supply to 100-percentWBC reduced. However, significant disagreement remains among transfusion medicine specialists with respect to the scientific and clinical justification for mandated ULR. ${ }^{14}$

Modern medical practice unquestionably requires an adequate, reliable blood supply that is made as safe as possible by using current technologies. To achieve these ends, the US blood supply is overseen and regulated through a network of programs that operate at the national level. ${ }^{15} \mathrm{By}$ these efforts, the US blood supply has never been safer. ${ }^{1}$ As may be anticipated, though, the stringent oversight and manufacturing process regulations that are imposed to ensure blood quality and safety are not cost-free; in fact, each new technology or process has increased costs. It has been 
estimated that ULR will increase the cost of blood services in the United States by at least $\$ 500$ million annually. ${ }^{8}$

Because of the intertwined-and, in some cases, discordant—clinical, safety, availability, and cost issues involved, blood evokes emotions and controversy that often seem to pit major stakeholders in the US health care system against one another. As a consequence, WBC reduction, and in particular the proposal for ULR, has become controversial. The University HealthSystem Consortium (UHC), an alliance of more than 80 academic medical centers, in response to its members' concerns, convened an Expert Panel to develop evidence-based recommendations for the use of WBC reduced cellular blood components. This article summarizes the findings of the UHC Expert Panel.

\section{ORGANIZATION AND PREPARATION OF THE EXPERT PANEL}

A systematic, qualitative review of the clinical literature was performed to identify published evidence related to the safety, efficacy, and utility ofWBC reduced cellular blood components. Evidence was obtained through a computer-based search of the National Library of Medicine's MEDLINE reference database (http:/ /www.ncbi.nlm.nih.gov/PubMed/). Fifteen review articles containing the keywords "leuko- reduced" and "blood" that were published in English in any field between 1990 and August 2000 were retrieved. The reference list for each article was examined to identify reviews missed in the database search. The "related articles" function of MEDLINE was used to identify 115 more citations on WBC reduced blood that were screened for their relevance.

MEDLINE was subsequently searched to identify English-language reports of original data on WBC reduced blood (human clinical use only, randomized trials, editorials, letters, comments). A total of 135 citations in this category were identified for the period between January 1, 1990 and August 1,2000 . The reference list of each article retrieved was examined to identify original work that had eluded the computer-based search; the "related articles" function of MEDLINE also was used for this purpose. A bibliography

\section{TABLE 1. Clinical evidence grading system*}

Evidence grade Description

$\overline{\text { Type IObtained from at least one properly designed randomized }}$ controlled trial

Type II-1 Obtained from well-designed controlled trials without randomization

Type II-2 Obtained from well-designed cohort or case-control analytic studies, preferably from more than one center or research group

Type II-3 Obtained from multiple time series with or without the intervention; dramatic results in uncontrolled experiments could also be regarded as this type of evidence

Type IIIOpinions of respected authorities, based on clinical experience, descriptive studies, or reports of expert committees

Type IV Insufficient to determine role

* Data taken from Guide to clinical preventive services-an assessment of the effectiveness of 169 interventions. ${ }^{17}$

comprising 173 articles (reviews, meta-analyses, original research, editorials) was compiled for the UHC Expert Panel before the committee meeting.

A modified grading system was used to categorize the levels of evidence according to study design, ${ }^{16-18}$ as summarized in Table 1. Data from randomized controlled trials were considered relatively reliable evidence of the clinical effectiveness ofWBC reduced blood. Uncontrolled open series, cohort studies, retrospective analyses, and case reports were considered less reliable sources of data. An evidence grade of Type IV was reserved for situations in which panel members felt a decision on use could not be determined because of insufficient or conflicting evidence. In any case, the evidence grading system does not reflect the strength of recommendation, but instead measures the strength of the available data.

The composition and conduct of the UHC Expert Panel were determined by using as a conceptual framework elements of the NIH Consensus Development Program. ${ }^{19} \mathrm{ARe}-$ quest for Consultants was sent directly to each UHC member institution. Candidates were initially identified on the basis of their knowledge of and clinical experience in blood banking and transfusion medicine. Panel bias was minimized

\begin{tabular}{|c|c|c|}
\hline \multicolumn{3}{|c|}{ TABLE 2. Clinical recommendation grading system* } \\
\hline Recommendation & Group consensus & Definition \\
\hline Class I & $\begin{array}{l}\text { Unanimous or nearly unanimous } \\
\text { in favor of the recommendation }\end{array}$ & $\begin{array}{l}\text { Conditions for which there is evidence and/or general agreement that } \\
\text { WBC reduction, or the use of WBC-reduced components, is useful } \\
\text { and effective }\end{array}$ \\
\hline Class II-a & $\begin{array}{l}\text { Majority in favor of } \\
\text { the recommendation }\end{array}$ & $\begin{array}{l}\text { Conditions for which there is conflicting evidence and/or a divergence } \\
\text { of opinion about the usefulness/efficacy of WBC reduction or the } \\
\text { use of WBC-reduced components; the weight of evidence/opinion is } \\
\text { in favor of usefulness/efficacy }\end{array}$ \\
\hline Class II-b & $\begin{array}{l}\text { Majority in favor of } \\
\text { the recommendation }\end{array}$ & $\begin{array}{l}\text { Conditions for which there is conflicting evidence and/or a divergence } \\
\text { of opinion about the usefulness/efficacy of WBC reduction or the } \\
\text { use of WBC-reduced components; usefulness/efficacy is less well } \\
\text { established by evidence/opinion }\end{array}$ \\
\hline Class III & $\begin{array}{l}\text { Unanimous or nearly unanimous } \\
\text { against the recommendation }\end{array}$ & $\begin{array}{l}\text { Conditions for which there is evidence and/or general agreement that } \\
\text { WBC reduction or the use of WBC-reduced components is not use- } \\
\text { ful/effective and in some cases may be harmful }\end{array}$ \\
\hline
\end{tabular}


by eliminating from consideration strong advocates either for or against ULR. The Expert Panel comprised seven experienced UHC faculty physicians in hematology, immunology, pathology, or transfusion medicine who are active in patient care. Each panelist signed a financial conflict-of-interest statement and a pledge of objectivity before final appointment to and acceptance of the position. No honorarium or other financial compensation was offered to any panelist. The day before the Expert Panel meeting, all panelists attended a UHC-sponsored symposium that covered scientific, regulatory, supply, and academic medical center issues relevant to WBC reduction (see Appendix).

The UHC Expert Panel was charged to provide expert consultation to the UHC Clinical Practice Advancement Center Technology Assessment Group in preparing evidencebased recommendations for the use of WBC reduced cellular blood components. Draft questions and statements to be ad- dressed by the UHCExpert Panel and compiled evidence tables were prepared by two of the authors (TAR and JPC) and provided to each panelist before the group convened in Oak Brook, Illinois, in October 2000. Each recommendation represents the panel's majority position after consideration of the evidence available for each potential indication and an open voice vote. Disagreements were resolved by further discussion and voting until a consensus or majority was achieved.

Content experts who made presentations at the UHC symposium also attended the Expert Panel meeting for consultation as requested on points of contention with regard to the evidence or indications for WBC reduced blood (á list of these persons appears in the Acknowledgements). A UHC staff person (JPC) cochaired the meeting. All recommendations were graded according to a modified classification scheme defined by the American College of Cardiology and the American Heart Association (Table 2). ${ }^{20}$

\begin{tabular}{|c|c|c|}
\hline Recommendations & Class/Evidence grade & Group consensus \\
\hline \multicolumn{3}{|l|}{ Clinical } \\
\hline \multirow{2}{*}{\multicolumn{3}{|c|}{ WBC-reduced components are indicated }} \\
\hline \multirow{2}{*}{\multicolumn{3}{|c|}{$\begin{array}{l}\text { To decrease the incidence of subsequent refractoriness to platelet } \\
\text { transfusion caused by HLA alloimmunization in patients requiring }\end{array}$}} \\
\hline & & \\
\hline long-term platelet support & Class I/Type II-3 & \\
\hline To provide blood components with reduced risk for CMV transmission & Class I/Type II-3 & \\
\hline \multicolumn{3}{|l|}{$\begin{array}{l}\text { To prevent FNHTR in patients who have had one or more documented } \\
\text { FNHTR }\end{array}$} \\
\hline \multirow{2}{*}{$\begin{array}{l}\text { To decrease the incidence of HLA alloimmunization in nonhepatic } \\
\text { solid-organ transplant candidates }\end{array}$} & Class III/Type I & \\
\hline & Class III/Type I & \\
\hline \multicolumn{3}{|l|}{ WBC-reduced components are not indicated } \\
\hline \multicolumn{3}{|l|}{ To prevent reactivation of endogenous viral infections such as CMV } \\
\hline To guard against general immunomodulatory effects: to decrease the & Class III/Type I & \\
\hline \multirow{2}{*}{$\begin{array}{l}\text { incidence of cancer recurrence, to decrease the incidence of post } \\
\text { operative infections, or to decrease postoperative mortality }\end{array}$} & Class III/Type III & \\
\hline & Class III/Type IV & \\
\hline \multicolumn{3}{|l|}{ To reduce hospital LOS in transfusion recipients } \\
\hline \multicolumn{3}{|l|}{ To prevent transfusion-associated GVHD or TRALI } \\
\hline \multicolumn{3}{|l|}{ To prevent bacterial sepsis } \\
\hline \multicolumn{3}{|l|}{$\begin{array}{l}\text { To prevent transmission of HTLV-I/II, EBV, HHV-8, or other, } \\
\text { unknown infectious agents }\end{array}$} \\
\hline To prevent transmission of VCJD or other prion diseases & Class II-b/Type IV & \\
\hline \multicolumn{3}{|l|}{$\begin{array}{l}\text { Io prevent transmission of vCJD or other prion diseases } \\
\text { Administrative }\end{array}$} \\
\hline \multicolumn{3}{|l|}{$\begin{array}{l}\text { for the preparation of RBC and nonapheresis platelet components } \\
\text { in community blood centers or hospital-based blood banks }\end{array}$} \\
\hline \multicolumn{3}{|l|}{$\begin{array}{l}\text { The implementation of ULR for purposes of establishing or maintaining } \\
\text { a single inventory of RBCs and platelets is not justified from a } \\
\text { scientific or policy perspective }\end{array}$} \\
\hline \multicolumn{3}{|l|}{ Policy } \\
\hline \multicolumn{3}{|l|}{$\begin{array}{l}\text { The benefit-to-risk ratio associated with WBC reduction is not sufficient } \\
\text { to justify requiring the ULR of all non-WBC (RBCs and platelets) }\end{array}$} \\
\hline cellular transfusion components & & Majority ( 5 to 2 in favor) \\
\hline \multicolumn{3}{|l|}{ The benefit-to-cost ratio associated with WBC reduction is not sufficient } \\
\hline cellular transfusion components & \multicolumn{2}{|c|}{ to justify requiring the ULR of all non-WBC (RBCs and platelets) } \\
\hline \multirow{2}{*}{\multicolumn{3}{|c|}{$\begin{array}{l}\text { The implementation of ULR for purposes of ensuring harmony of blood } \\
\text { policy between the United States and other countries is not justified }\end{array}$}} \\
\hline & & \\
\hline \multicolumn{3}{|l|}{ The FDA should not mandate ULR of the US blood supply on the basis } \\
\hline of current scientific and medical evidence & & Unanimous \\
\hline
\end{tabular}




\section{THE EXPERT PANEL'S RECOMMENDATIONS}

The UHC Expert Panel developed clinical, administrative, and policy recommendations for the use ofWBC reduced components, based on information from several sources: the published medical literature; the UHC-sponsored symposium on ULR; and each panelist's clinical experience. The UHC recommendations are reviewed here and are summarized in Table 3 .

\section{Clinical recommendations for WBC reduced blood components}

Indications are uses that the UHC Expert Panel believes are supported by published evidence and clinical experience. Nonindications are uses that the panel believes are not supported or justified by published clinical evidence or clinical experience.

\section{Indications for WBC reduced blood components}

Indication 1: To decrease the incidence of subsequent refractoriness to platelet transfusion caused by HLA alloimmunization in patients requiring long-term platelet support (Class I/Type I).

This unanimous recommendation was based on the results of eight randomized trials of WBC reduced components as a means of reducing HLA alloimmunization and platelet refractoriness. ${ }^{21-28}$ The composite data show a clear trend toward less formation of HLA alloantibodies in recipients of WBC reduced components than in those of nonmodified components. However, the panel warned that clinical extrapolation of these findings to other patient groups is not justified, for several reasons. First, the subjects in the published trials were immunosuppressed, by virtue either of their underlying illness (malignancies) or of the receipt of cytotoxic therapy, and they required multiple platelet transfusions. Second, the WBC reduction methods used were not the same in all studies and are significantly different from those available at present. Third, all but one of the individual studies were insufficiently powered to provide definitive information on this topic. ${ }^{28}$ The UHC Expert Panel therefore concurred that current clinical evidence does not show that WBC reduced cellular components would provide clinically relevant benefits to immunocompetent patients who require a transfusion under acute circumstances, such as elective surgery, trauma, or other situations that result in significant blood loss.

Indication 2: To provide blood components with reduced risk for CMV transmission (Class I/Type I).

The Expert Panel concluded by a 6-to-1 vote that current $\mathrm{WBC}$ reduction methods and manufacturing standards yield components that may be considered equivalent to CMVseronegative components. This recommendation is based on substantial Type I data that consistently show the nearly to- tal elimination of CMV transmission via WBC reduced RBCs and platelets. ${ }^{29-37}$ It was, however, noted that these results were obtained primarily in patients who were undergoing cytotoxic chemotherapy, and thus they may not be applicable to all immunosuppressed individuals. A decision to order WBC reduced components in lieu of CMV-seronegative blood should be based on the potential susceptibility of each patient to disseminated CMV infection, as implied by his or her immune status, underlying comorbidities, and overall physical condition. ${ }^{38}$

Indication 3: To prevent a subsequent FNHTR in patients who have had one documented FNHTR (Class I/Type II-3).

The UHC Expert Panel voted 6 to 1 in favor of this indication, stressing that this recommendation applies to both platelet and RBC transfusions. The panelists concurred that the use of WBC reduced components will not prevent all FNHTRs, regardless of indication or patient subset. No published data are available from randomized trials that by design examined the potential impact of WBC reduced components on the incidence of FNHTR. ${ }^{8}$

Indication 4: To decrease the incidence of HLA alloimmunization in nonhepatic solid-organ transplant candidates (Class I/Type II-3).

This unanimous recommendation applies to platelet and RBC transfusions. The panel was not aware of any data from randomized clinical trials specifically addressing the role of WBC reduced blood in transplantation outcomes. Several panelists further noted that heart and kidney transplantation must be considered different from liver transplantation, because of differences in HLA presentation and immunoreactivity in those organs. Because significant clinical data clearly show a lower incidence of transfusion-associated HLA alloimmunization in patients who receiveWBC reduced components, ${ }^{28}$ the panelists believe that WBC reduced components could reasonably be expected to be beneficial in nonhepatic transplant candidates.

\section{Nonindications for WBC reduced blood components}

Nonindication 1: To prevent reactivation of endogenous viral infections such as HIV or CMV (Class III/Type I).

The UHC Expert Panel concluded unanimously that WBC reduced components do not affect the risk of reactivation of endogenous viral infection in allogeneic transfusion recipients, as determined primarily from the results of the Viral Activation Transfusion Study (VATS) ${ }^{39}$ The panel was not aware of any other clinical trials that have directly examined the possible impact of $\mathrm{WBC}$ reduction in this situation.

Nonindication 2: To guard against general immunomodulatory effects: to decrease the incidence of cancer recurrence; to decrease the incidence of postoperative infections; or to decrease postoperative mortality (Class III/Type I). 
Five published Type I studies ${ }^{40-44}$ were considered by the UHC Expert Panel in making this unanimous recommendation. While some data suggest greater risk for postoperative infections in patients who receive standard components than in those who receive WBC reduced components, the effect of WBC reduced blood on cancer recurrence or postoperative mortality is unclear. Moreover, a host of potentially confounding variables makes it difficult to compare results among the studies. These include, but are not limited to, differences in study design (single- vs. multi-center), patient populations, the methods used toWBC reduce components, and the residual $\mathrm{WBC}$ content of the components that were actually transfused. ${ }^{10,45,46}$

Nonindication 3: To reduce length of hospital stay in transfusion recipients (Class III/Type I).

The UHC Expert Panel was unanimous in this recommendation. Length of stay (LOS) in hospital is a topic of great interest from the institutional perspective, because of the potentially significant cost savings or cost avoidance associated with its reduction. The only published Type I study that specifically examined this issue showed that the average LOS for cardiac surgery patients who received WBC reduced blood was not significantly different from that for patients who received standard components. ${ }^{44}$ Clinical trials ofWBC reduced components that incorporate LOS as a primary endpoint would be of substantial value in shaping public policy as it relates to ULR.

Nonindication 4: To prevent transfusion-associated GVHD or transfusion-related acutelung injury (TRALI) (Class III/Type I).

The UHC Expert Panel concluded unanimously that WBC-reduced components have no role in preventing transfusion-associated GVHD or TRALI. Transfusion of viable WBCs may result in GVHD, particularly in immunosuppressed individuals. ${ }^{47}$ Pretransfusion irradiation of blood, which inhibits the proliferation of donor lymphocytes but has no significant effect on RBC, platelet, or granulocyte function, is used routinely to prevent this complication. By contrast, TRALI appears to be caused by antibodies or other soluble substances in donor plasma that react with recipient granulocytes, leading to increased permeability of the pulmonary microcirculation. ${ }^{1}$ Thus, because WBC reduction procedures do not specifically remove plasmatic solutes from blood, the use of WBC reduced components would not reduce the risk of TRALI.

Nonindication 5: To prevent bacterial sepsis (Class III/ Type III).

Bacterial contamination of cellular components is a rare event with potential sources that include the blood collection system, an inadequately cleaned donor skin site, or unrecognized donor bacteremia. While the true frequency of transfusion-associated bacterial infection is not known, it occurs more often with platelets than with RBCs, presumably because of differences in the methods used to prepare and store these components. Data from in vitro studies show that prestorage WBC reduction removes bacteria (most prominently, Yersinia enterocolitica) from contaminated blood components. ${ }^{7}$ Because no data are available from comparative clinical studies of WBC reduction as a means of reducing transfusion-associated bacterial infection, however, the UHC Expert Panel concurred unanimously that WBC reduction is not indicated for this purpose.

Nonindication 6: To prevent transmission of HTLV-I/ II, EBV, human herpesvirus 8 (HHV-8), or other, unknown infectious agents (Class III/Type IV).

The UHC Expert Panel unanimously held that WBC reduced components are not indicated as a means of preventing the transmission of HTLV-I/II, EBV, HHV-8, or other, unknown infectious agents. All of these viruses are believed to be sequestered in WBCs and thus are potentially transmissible via RBC and platelet preparations. However, no clinical data are available from studies in which WBC reduced components were compared with nonmodified versions as vectors for infection. ${ }^{8}$

Nonindication 7: To prevent transmission of vCJD or other prion diseases (Class III/Type IV).

The UHC Expert Panel unanimously recommended that WBC reduced blood components are not indicated as a means of preventing the transmission of vCJD or other prion diseases. Data from animal studies and case reports suggest the possibility that CJD may be transmitted by the transfusion of blood or albumin. ${ }^{13}$ However, no confirmed case of CJD has been attributed to the transfusion of blood or other blood derivatives, nor has any cluster of CJD been reported after the administration of a pooled plasma derivative that was known to contain units obtained from a donor who subsequently developed CJD. ${ }^{13}$ Further, because prions are found in plasma independent of WBCs, WBC reduction by itself may be ineffective as a preventive measure.

\section{Administrative recommendations}

The UHC Expert Panel considered a number of issues that were categorized as administrative rather than clinical. These are discussed in the next few paragraphs.

Recommendation 1: The use of prestorage methods for WBC reduction is recommended for the preparation of RBC and nonapheresis platelet components in community blood centers or hospital-based blood banks (Platelets: Class I/Type II-1; RBCs: Class IIa/Type III).

A number of in vitro studies have shown that WBC-derived proinflammatory cytokines (IL-1, IL-6, and TNF $\alpha$ ), chemokines, complement fragments, histamine, and lipids accumulate to clinically significant levels in the plasma of 
platelet concentrates (PCs) during storage. ${ }^{48}$ These have been postulated to be etiologically involved with a majority $(>85 \%)$ of FNHTRs to platelets. A direct role for WBC-derived bioreactive substances in eliciting transfusion reactions is supported by the results of a randomized trial in which patients who received a transfusion of the cytokine-rich plasma component prepared from standard PCs experienced a significantly higher incidence of severe reactions than the same patients who received reconstituted, cytokine-depleted platelets from the same unit. ${ }^{49}$ These investigators further reported that the concentrations of IL- $1 \beta$ and IL- 6 in the plasma correlated positively with theWBC count in the platelet component. A subsequent randomized trial demonstrated that poststorage removal of cytokine-replete plasma from PCs was more effective than poststorage WBC reduction using bedside filtration in preventing severe FNHTRs to platelets. ${ }^{50}$ Together, these results provide sufficient justification for recommending prestorage $\mathrm{WBC}$ reduction as the preferred means of minimizing FNHTRs in recipients of pooled random-donor platelets. However, no data from a randomized, controlled trial directly demonstrate the clinical effectiveness of prestorage $\mathrm{WBC}$ reduction of platelets in the prevention of FNHTR.

In contrast to PCs, RBC concentrates accumulate bioreactive substances at consistently lower levels, most likely as a result of their storage at $4^{\circ} \mathrm{C}$, and perhaps also of the types and numbers of WBCs present in the RBC component. ${ }^{50}$ No data from randomized trials show a causal relationship between storage-generated cytokines and acute febrile reactions to RBCs. Rather, most FNHTRs in RBC recipients appear to be mediated by a reaction between incompatible donorWBCs present in the RBC unit and antibodies in the recipient's plasma. ${ }^{48}$ Because WBCs are responsible for RBC-induced FNHTRs, poststorage or bedside filtration is an effective way to minimize such reactions. ${ }^{8}$ However, as it is difficult to ensure adequate QC with bedside filtration, the UHC Expert Panel recommends the use of prestorage WBC reduced RBC concentrates when WBC reduced cells are indicated.

Recommendation 2: The implementation of ULR for purposes of establishing or maintaining a single inventory of RBCs and platelets is not justified from a scientific or policy perspective (Class II-b/Type IV).

The UHC Expert Panel unanimously recommends that inventory management considerations should not constitute an overriding basis for community blood banks or hospitals to convert to 100-percent use of WBC reduced components. This issue has not been studied systematically to determine the impact of a single inventory on operations, safety, or uniformity in the delivery of blood services. The panelists believe that inventory management is a local issue that must remain flexible in the context of prevailing conditions.

\section{Policy recommendations}

The UHC Expert Panel considered four issues relevant to national blood policy and made the following recommendations.

Recommendation 1: The benefit-to-risk ratio associated with WBC reduction is not sufficient to justify requiring the ULR of all non-WBC (i.e., RBCs and platelets) cellular transfusion components.

The UHC Expert Panel voted 5 to 2 that WBC reduced RBCs and platelets provide significant and necessary clinical benefits in specific subsets of patients, as recommended in Table 3. The panel noted a finite (small) risk for an adverse event, such as red-eye syndrome or a drop in blood pressure, that was associated with the use ofWBC reduced components in any group of patients regardless of indication, although this refers particularly to components produced by bedside filtration. Given the equivalence of risk with the use of WBC reduced components in all patients, the benefit-to-risk ratio would be expected to become very large in patients who truly require WBC reduced blood. By contrast, because there is no proven clinical benefit associated with the use of WBC reduced components for indications other than the four recommended in this assessment, the numerator of the benefit-to-risk ratio goes to zero in the nonrecommended scenarios. If the denominator of the ratio remains the same small number for WBC reduced components in all patients, this ratio therefore would go to zero or some exceedingly small number that would presumably be less than the ratio for patients who truly benefit from receiving WBC reduced components. Finally, with respect to the term "universal," most patients who require WBC reduced components already receive such components under current medical practice. Thus, the panel found that ULR cannot be justified on the basis of either published clinical evidence or experience.

Several panelists further warned that a federal mandate for ULR could have a number of unintended, deleterious consequences secondary to the supply and potency of specific components. For example, donors who are sickle-cell trait carriers or who have other conditions that are not amenable to WBC reduction procedures would be excluded from donation, or their donor units may be wasted in unsuccessful postdonation modification. A counter-argument proposed in favor of mandated ULR is that it would ensure that all patients for whom WBC reduced cellular components are indicated would receive them.

Recommendation 2: The benefit-to-cost ratio associated with $W B C$ reduction is not sufficient to justify requiring the ULR of all non-WBC (i.e., RBCs and platelets) cellular transfusion components.

The UHC Expert Panel unanimously concluded that the benefit-to-cost ratio associated with WBC reduction is not 
sufficient to justify mandating ULR in the US blood system. No data from controlled trials are available to resolve this issue in terms of hospital costs, LOS, other costs of treatment, or cost avoidance due to fewer transfusion-related adverse events in patients who receive WBC reduced components, as compared with those factors in patients given standard units. ${ }^{5,8}$

The panel strongly believes that, while the US blood supply itself is as safe as possible with current technology, the system for delivering transfusion services is at risk. An FDA mandate for ULR without adequate reimbursement through the existing inpatient DRG system will result in a direct impact of the increased costs on the institutional blood banks' budgets. Historically, the unreimbursed costs of mandated ULR will be accommodated through staff reductions and cutbacks that will undoubtedly increase the chances for error and thereby raise the risks of transfusion-related morbidity and mortality. Diversion of these health care resources into ULR thus could pose a greater threat to all patients than that posed by non-WBC reduced blood in most patients. The panel also was unanimous in its belief that it is inappropriate and nonproductive to discuss the premise of ULR in the absence of cost considerations, given the delicate financial situations of a great many US hospitals.

Recommendation 3: The implementation of ULR for purposes of ensuring harmony of blood policy between the United States and other countries is not justified from a scientific or policy perspective.

This unanimous recommendation was not based in science but instead was deemed a policy issue related to US leadership in medical science and health care. With the possible exception of overseas commercial marketing of blood and blood components, there is no reason for the United States to adopt ULR to harmonize with the policies of other countries. The UHC Expert Panel strongly believes that the United States should continue to exercise leadership in science and medical technology, with evidence-based decision making at the core of its health care system.

Recommendation 4: The FDA should not mandate ULR of the US blood supply on the basis of current scientific and medical evidence.

The UHC Expert Panel concurred that FDA action is appropriate and necessary to protect the public health in the face of an acute threat, as starkly exemplified by the discovery of HIV in donated blood more than 20 years ago. However, the panel was unanimous in its belief that allogeneic passenger WBCs do not pose a significant clinical risk to the vast majority of patients who require component transfusions under acute circumstances. Therefore, the FDA should not implement mandatory ULR. Selective use ofWBC reduced components as indicated remains the preferred approach. The panel also warned that, should ULR become a manufacturing requirement in the United States, further clinical research in this area will likely become difficult, if not impossible, to justify from an ethical and financial perspective.

\section{CONCLUSION}

Blood is an indispensable component of the modern health care armamentarium that can be viewed dichotomously. From one perspective, blood is a life-sustaining clinical asset that provides well-known clinical benefits to patients who require a transfusion. By contrast, although the US blood supply has never been safer, allogeneic transfusion still entails a plethora of potential risks, a number of which are associated with significant morbidity and mortality. ${ }^{1,51}$ Transfusiontransmitted infections are well documented, especially HIV, $\mathrm{HBV}$, and $\mathrm{HCV}$, as well as pathogenic bacteria. ${ }^{1,52}$ Overall, the risks for transfusion-related infections are relatively low, and they appear to be declining in the US blood supply. ${ }^{53}$ Despite this decline, however, blood safety remains a subject of concern to many patients and to some physicians. ${ }^{54-56}$

The UHC Expert Panel concurred that WBC reduced RBCs and platelets provide significant, real, and necessary clinical benefits in selected subsets of patients, who already receive such components under current medical practice. By contrast, the panel firmly believes that current clinical evidence is insufficient to demonstrate that the use ofWBC reduced components in patients outside these specific groups provides significant, clinically relevant benefits that are not obtained with non-WBC reduced components. Given this position, the panel indicated substantial concern that an unfunded mandate for ULR would have a number of unintended, deleterious consequences secondary to the supply and potency of specific components, such as those from persons who are sickle-cell trait carriers or who have other conditions that are not amenable to WBC reduction procedures or are in short supply, such as rare phenotypes. They further suggested that the current lack of an adequate reimbursement mechanism through the existing inpatient DRG system will result in a direct impact of the increased cost on the hospitals' blood bank budget. On the basis of their experience, the members of the panel are concerned that the added costs of mandated ULR will be accommodated through staff reductions and cutbacks that will increase the chances for systemic clerical errors. This will thereby raise the risk of transfusion-related morbidity and mortality for all blood recipients. Finally, the panel unanimously believes that it is inappropriate and nonproductive to discuss the premise of ULR in the absence of cost considerations, given the beleaguered financial situations of a great number of US academic medical centers.

The UHC consensus recommendations for the use of WBC reduced cellular blood components represent an objective synthesis of the latest scientific and clinical evidence, in the context of substantial practical experience. They are, 
of course, subject to interpretation and modification to reflect local variations in medical standards of practice, the individualization of patient care, physician experience, patient demographics, or institutional policies and procedures. It is imperative, however, that all of the participants involved in the US health care enterprise - in particular, the blood safety and regulatory agencies, the blood supply organizations, the institutional decisionmakers, and individual practitionerskeep in mind that medical science is dynamic and continuously evolving. It often is not definitive, and its findings frequently are not generally applicable in practice. The corollary follows that clinical guidelines, recommendations, or regulations, however limited or broad-based in scope, should reflect a consensus that considers the available evidence within the context of the realities of the modern US health care delivery system.

\section{ACKNOWLEDGMENTS}

The authors acknowledge the following persons who presented symposium topics and provided expert consultation to the UHC panel in its deliberations: James AuBuchon, MD; Mark Brecher, MD; Linda Chambers, MD; Walter Dzik, MD; Terry Gernsheimer, MD; Lawrence Goodnough, MD; Steven Kleinman, MD; Jong-Hoon Lee, MD; Leo McCarthy, MD; Stephen Nightingale, MD; Lawrence Petz, MD; Edward Snyder, MD; Ronald Strauss, MD; and Eleftherios Vamvakas, $\mathrm{MD}$, PhD. A special note of thanks goes to the group's Executive Secretary, Kathy Massillo, who was responsible for the logistics and execution of the UHC symposium on ULR and the Expert Panel meeting.

\section{APPENDIX 1. INVITED SPEAKERS FOR THE UHC SYMPOSIUM ON ULR}

\section{WBC Reduction of Cellular Blood Components:} Scientific, Clinical, and Economic Issues

Ronald Strauss, MD, University of Iowa Hospitals and Clinics-Selective versus Universal Leukocyte Reduction: A Quandary of Scientific/Political/Economic Decisions

Terry Gernsheimer, MD, University of Washington Medical Center-Leuko reduction and HIV: The Results of the VATS Trial

Eleftherios Vamvakas, MD, PhD, New York University Medical Center-Transfusion-Associated Immunomodulation: Is it Time for Universal White Cell Reduction?

Walter Dzik, MD, Massachusetts General Hospital—Does Leuko reduction Shorten Hospital Length of Stay?

Steven Kleinman, MD, University of British ColumbiaLeuko reduction and Variant CJD: Formulating Policy in the Absence of Data

James AuBuchon, MD, Dartmouth-Hitchcock Medical Center-Economic Implications of Universal Leuko reduction

\section{WBC Reduction of Cellular Blood Components: Regulatory and Supply Issues}

Linda Chambers, MD, American Red Cross-The American Red Cross as an Advocate for Universal and Prestorage Leuko reduction

Jong-Hoon Lee, MD, Blood and Plasma Branch, Center for Biologics Evaluation and Research, FDA-Leukocyte Reduction: FDA's Current Thinking

Stephen Nightingale, MD, Office of Public Health and Science, DHHS-Leukocyte Reduction: U.S. DHHS Perspective

\section{WBC Reduction of Cellular Blood Components in Academic Medical Centers}

Harold Oberman, MD, University of Michigan Medical Center-Leukocyte Reduction at the University of Michigan Medical Center

Mark Brecher, MD, University of North Carolina at Chapel Hill-Universal Leuko reduction at The University of North Carolina: Why We Switched

Lawrence Petz, MD, UCLA Medical Center-Universal Leukocyte Reduction as Seen From the Perspective of Hospital-Based Physicians

Edward Snyder, MD, Yale-New Haven Hospital-Universal Leuko reduction: Ivory Tower or Better Medical Care?

Leo McCarthy, MD, Indiana University Medical CenterLeuko reduction at Clarian Health: Impact on Transfusion Reactions and Implications for a Large Transfusion Service

Lawrence Goodnough, MD, Washington University Medical School-Leuko reduction at Barnes-Jewish Hospital

\section{REFERENCES}

1. Goodnough LT, Brecher ME, Kanter MH, AuBuchon JP. Transfusion medicine. First of two parts-blood transfusion. N Engl J Med 1999;340:438-47.

2. Hogman CF. Improved utilization of blood due to systematic fractionation. Qual Assur Health Care 1990;2:207-12.

3. Carter TH. Biotechnology, economics, and the business of blood. Biotechnology 1991;19:3-30.

4. Lawrence VA, Birch S, Gafni A. The impact of new clinical guidelines on the North American blood economy. Transfus Med Rev 1994;8:232-41.

5. Lane TA. Leukocyte reduction of cellular blood components. Effectiveness, benefits, quality control, and costs. Arch Pathol Lab Med 1994;118:392-404.

6. Heaton WA, Rebulla P, Pappalettera M, Dzik WH. A comparative analysis of different methods for routine blood component preparation. Transfus Med Rev 1997;11:11629.

7. Miller JP, Mintz PD. The use of leukocyte-reduced blood components. Hematol Oncol Clin North Am 1995;9:69-90. 
8. Dzik S, AuBuchon J, Jeffries L, et al. Leukocyte reduction of blood components: public policy and new technology. Transfus Med Rev 2000;14:34-52.

9. Heddle NM, Blajchman MA. The leukodepletion of cellular blood products in the prevention of HLA-

alloimmunization and refractoriness to allogeneic platelet transfusions. Blood 1995;85:603-6.

10. Vamvakas EC. Transfusion-associated cancer recurrence and postoperative infection: meta-analysis of randomized, controlled clinical trials. Transfusion 1996;36:175-86.

11. Heiss MM. Risk of allogeneic transfusions. Br J Anaesth 1998;81:16-9.

12. Marquet RL, Busch OR, Jeekel J, et al. Are allogeneic blood transfusions acceptable in elective surgery in colorectal carcinoma? Eur J Cancer 1998;35:352-60.

13. Vamvakas EC. Risk of transmission of Creutzfeldt-Jakob disease by transfusion of blood, plasma, and plasma derivatives. J Clin Apheresis 1999;14:135-43.

14. Thurer RL, Luban NLC, AuBuchon JP, et al. Universal WBC reduction (letter). Transfusion 2000;6:751-2.

15. Busch M, Chamberland M, Epstein J, et al. Oversight and monitoring of blood safety in the United States. Vox Sang 1999;77:67-76.

16. Goldbloom R, Battista RN. The periodic health examination: 1. Introduction. CMAJ 1988;138:617-8.

17. Guide to clinical preventive services-an assessment of the effectiveness of 169 interventions. U.S. Preventive Services Task Force. Baltimore: Williams \& Wilkins, 1989:xxvii-xxxviii.

18. Cook DJ, Guyatt GH, Laupacis A, et al. Rules of evidence and clinical recommendations on the use of antithrombotic agents. Chest 1992;102(4 Suppl):305S-11S.

19. Ferguson JH. The NIH Consensus Development Program. The evolution of guidelines. Int J Technol Assess Health Care 1996;12:460-74.

20. Braunwald E, Antman EM, Beasley JW, et al. ACC/AHA guidelines for the management of patients with unstable angina and non-ST-segment elevation myocardial infarction. A report of the American College of Cardiology/ American Heart Association Task Force on Practice Guidelines (Committee on the Management of Patients with Unstable Angina). J Am Coll Cardiol 2000;36:970-1062.

21. Schiffer CA, Dutcher JP, Aisner J, et al. A randomized trial of leukocyte-depleted platelet transfusion to modify alloimmunization in patients with leukemia. Blood 1983;62:815-20.

22. Andreu G, Dewailly J, Leberre C, et al. Prevention of HLA immunization with leukocyte-poor packed red cells and platelet concentrates obtained by filtration. Blood 1988;72:964-9.

23. Sniecinski I, O’Donnell MR, Nowicki B, Hill LR. Prevention of refractoriness and HLA-alloimmunization using filtered blood products. Blood 1988;71:1402-7.

24. Oksanen K, Kekomäki R, Ruutu T, et al. Prevention of alloimmunization in patients with acute leukemia by use of white cell-reduced blood components-a randomized trial. Transfusion 1991;31:588-94.

25. Van Marwijk Kooy M, van Prooijen HC, Moes M, et al. Use of leukocyte-depleted platelet concentrates for the prevention of refractoriness and primary HLA alloimmunization: a prospective, randomized trial. Blood 1991;77:201-5.

26. Williamson LM, Wimperis JZ, Williamson P, et al. Bedside filtration of blood products in the prevention of HLA alloimmunization-a prospective, randomized study. Alloimmunisation Study Group. Blood 1994;83:3028-35.

27. Sintnicolaas K, van Marwijk Kooij M, van Prooijen HC, et al. Leukocyte depletion of random single-donor platelet transfusions does not prevent secondary human leukocyte antigen-alloimmunization and refractoriness: a randomized prospective study. Blood 1995;85:824-8.

28. Leukocyte reduction and ultraviolet B irradiation of platelets to prevent alloimmunization and refractoriness to platelet transfusions. The Trial to Reduce Alloimmunization to Platelets Study Group. N Engl J Med 1997;337:1861-9.

29. Verdonck LF, de Graan-Hentzen YC, Dekker AW, et al. Cytomegalovirus seronegative platelets and leukocyte-poor red blood cells from random donors can prevent primary cytomegalovirus infection after bone marrow transplantation. Bone Marrow Transplant 1987;2:73-8.

30. De Graan-Hentzen YCE, Gratama JW, Mudde GC, et al. Prevention of primary cytomegalovirus infection in patients with hematologic malignancies by intensive white cell depletion of blood products. Transfusion 1989;29:757-60.

31. Gilbert GL, Hayes K, Hudson IL, James J. Prevention of transfusion-acquired cytomegalovirus infection in infants by blood filtration to remove leukocytes. The Neonatal Cytomegalovirus Infection Study Group. Lancet 1989;1:1228-31.

32. De Witte T, Schattenberg A, Van Dijk BA, et al. Prevention of primary cytomegalovirus infection after allogeneic bone marrow transplantation by using leukocyte-poor random blood products from cytomegalovirusunscreened blood-bank donors. Transplantation 1990;50:964-8.

33. Bowden RA, Slichter SJ, Sayers M, et al. Use of leukocyte-depleted platelets and cytomegalovirus-seronegative red blood cells for prevention of primary cytomegalovirus infection after marrow transplantation. Blood 1991;78:246-50.

34. Eisenfeld L, Silver H, McLaughlin J, et al. Prevention of transfusion-associated cytomegalovirus infection in neonatal patients by the removal of white cells from blood. Transfusion 1992;32:205-9.

35. Van Prooijen HC, Visser JJ, van Oostendorp WR, et al. Prevention of primary transfusion-associated cytomegalovirus infection in bone marrow transplant recipients by the removal of white cells from blood components with highaffinity filters. Br J Haematol 1994;87:144-7. 
36. Bowden RA, Slichter SJ, Sayers M, et al. A comparison of filtered leukocyte-reduced and cytomegalovirus (CMV) seronegative blood products for the prevention of transfusion-associated CMV infection after marrow transplant. Blood 1995;86:3598-603.

37. Narvios AB, Przepiorka D, Tarrand J, et al. Transfusion support using filtered unscreened blood products for cytomegalovirus-negative allogeneic marrow transplant recipients. Bone Marrow Transplant 1998;22:575-7.

38. Preiksaitis JK. The cytomegalovirus-"safe" blood product: is leuko reduction equivalent to antibody screening? Transfus Med Rev 2000;14:112-36.

39. Collier AC, Kalish LA, Busch MP, et al. Leukocyte-reduced red blood cell transfusions in patients with anemia and human immunodeficiency virus infection: the Viral Activation Transfusion Study: a randomized controlled trial. JAMA 2001;285:1592-601.

40. Jensen LS, Andersen AJ, Christiansen PM, et al. Postoperative infection and natural killer cell function following blood transfusion in patients undergoing elective colorectal surgery. Br J Surg 1992;79:513-6.

41. Houbiers JG, Brand A, van de Watering LM, et al. Randomised controlled trial comparing transfusion of leucocyte-depleted or buffy-coat-depleted blood in surgery for colorectal cancer. Lancet 1994;344:573-8.

42. Jensen LS, Kissmeyer-Nielsen P, Wolff B, Qvist N. Randomised comparison of leucocyte-depleted versus buffy-coat-poor blood transfusion and complications after colorectal surgery. Lancet 1996;348:841-5.

43. Tartter PI, Mohandas K, Azar P, et al. Randomized trial comparing packed red cell blood transfusion with and without leukocyte depletion for gastrointestinal surgery. Am J Surg 1998;176:462-6.

44. Van de Watering LM, Hermans J, Houbiers JG, et al. Beneficial effects of leukocyte depletion of transfused blood on postoperative complications in patients undergoing cardiac surgery: a randomized clinical trial. Circulation 1998;97:562-8.

45. Vamvakas EC, Blajchman MA. Deleterious clinical effects of transfusion-associated immunomodulation: fact or fiction? Blood 2001;97:1180-95.

46. Vamvakas EC, Blajchman MA. Universal WBC reduction: the case for and against. Transfusion 2001;41:691-712.

47. Anderson KC, Weinstein HJ. Transfusion-associated graft-versus-host disease. N Engl J Med 1990;323:315-21.

48. Heddle NM. Pathophysiology of febrile nonhemolytic transfusion reactions. Curr Opin Hematol 1999;6:420-6.

49. Heddle NM, Klama L, Singer J, et al. The role of the plasma from platelet concentrates in transfusion reactions. N Engl J Med 1994;331:625-8.

50. Heddle NM, Klama L, Meyer R, et al. A randomized controlled trial comparing plasma removal with white cell reduction to prevent reactions to platelets. Transfusion 1999;39:231-8.

51. Ness PM. Transfusion medicine: an overview and update. Clin Chem 2000;46:1270-6.

52. Glynn SA, Kleinman SH, Schreiber GB, et al. Trends in incidence and prevalence of major transfusion-transmissible viral infections in US blood donors, 1991 to 1996. Retrovirus Epidemiology Donor Study (REDS). JAMA 2000;284:229-35.

53. Schreiber GB, Busch MP, Kleinman SH, Korelitz JJ. The risk of transfusion-transmitted viral infections. The Retrovirus Epidemiology Donor Study. N Engl J Med 1996;334:1685-90.

54. Holland PV. Viral infections and the blood supply (editorial). N Engl J Med 1996;334:1734-5.

55. Kruskall MS. The perils of platelet transfusions (editorial). N Engl J Med 1997;337:1914-5.

56. Klein HG. Will blood transfusion ever be safe enough? (editorial). JAMA 2000;284:238-40. 